\title{
Problemáticas da autoria e da camuflagem feminina em As Aventuras de Diófanes, de Teresa Margarida Silva e Orta*
}

\author{
Moizeis Sobreira de Sousa** \\ Fabio Mario da Silva***
}

\section{Resumo}

A obra Aventuras de Diófanes, de Teresa Margarida Silva e Orta, teve diversas edições, mas muitas delas ocultaram a autoria de Orta. O objetivo deste trabalho é apontar as possíveis razões que teriam levado à ocultação da autoria desse romance, o qual levanta muitas questões em torno da autoria feminina. Pretendese também discutir, a partir da análise da obra (observando também o diálogo com as Aventuras de Telêmaco de Fénelon, que é apresentado como parâmetro para a autora), o processo de camuflagem das personagens, o que contribui para problematizar as questões relativas ao feminino e ao masculino.

Palavras-chave: Autoria Feminina, Camuflagem, Romance, Teresa Margarida Silva e Orta.

" Recebido para publicação em 14 de julho de 2015, aceito em 4 de novembro de 2016.

** Pesquisador Colaborador do Instituto de Estudos da Linguagem da Universidade Estadual de Campinas (IEL/UNICAMP); Pós-doutorando em Teoria Literária com bolsa da Fundação de Amparo à Pesquisa do Estado de São Paulo (FAPESP), Campinas, SP, Brasil. moizeis.ssousa@gmail.com

*** Professor Adjunto de Literatura Portuguesa da Universidade Federal do Sul e Sudeste do Pará (UNIFESSPA), Marabá, PA, Brasil. famamario@gmail.com 
The Problematic of Authorship and of The Feminine Camouflage in The Adventures of Diáfanes by Teresa Margarida Silva e Orta

\begin{abstract}
The work The Adventures of Diófanes by Teresa Margarida Silva e Orta had diverse editions, but many of them concealed Orta's authorship. The purpose of this article is to point out the possible reasons that could have lead to the hiding of the authorship of this novel that raises many questions concerning the female authorship. Starting from the analysis of the work (observing also the dialogue with The Adventures of Telemachus by Fenelon, which is presented as a reference for the authoress) we also intend to discuss the process of camouflage of the characters, hat contributes to the problematizing of the questions related to the feminine and the masculine issues.
\end{abstract}

Keywords: Female Authorship, Camouflage, Teresa Margarida Silva e Orta. 
Durante muito tempo, a autoria de Aventuras de Diófanes ficou envolta em incertezas e o seu título foi alvo de sucessivas alterações. Na primeira edição, datada de 1752 , esse romance é atribuído ao pseudônimo Dorothea Engrássia Tavareda Dalmira e o título que surge estampado é Máximas de virtude e formosura com que Diófanes, Climenea e Hemirena, Príncipes de Tebas, venceram os mais apertados lances da desgraça. Na edição seguinte, publicada em 1777, Dorothea Engrássia permanece como autora, mas o nome do livro é alterado para Aventuras de Diófanes imitando o sapientíssimo Fénelon na sua Viagem de Telêmaco. ${ }^{1}$ Em 1790, quando surge a quarta edição, não se modifica o título anterior, no entanto Alexandre de Gusmão é apresentado como "seu verdadeiro autor". Por fim, na edição publicada em 1818, a obra se intitula História de Diófanes, Clymenea e Hemirena, Príncipes de Tebas. História Moral, e é atribuída a "huma senhora portuguesa", o que a torna uma obra anônima. É somente a partir de 1945, ano em que Rui Bloem publica uma edição no Rio de Janeiro, que o título é padronizado na forma Aventuras de Diófanes e a autoria é atribuída a quem de fato a escreveu, a saber: Teresa Margarida da Silva e Orta.

Parece razoável pensar que a indefinição relativa à autoria $e$ as alterações no título, sobretudo as que são observadas nas segunda e terceira edições, resultam de um estratagema editorial utilizado pela autora ou pelos seus editores, a fim de assegurar a publicação da obra e criar condições para que ela fosse bem recebida, além de conferir-lhe prestígio. Nesse sentido, referenciar Fénelon e suas Aventuras de Telêmaco na edição de 1777 pode ser entendido como uma forma de se associar à consagração de que gozava esse autor francês e seu romance entre o público do século XVIII. Da mesma forma, a invocação, em 1790, de Alexandre de Gusmão, de quem Teresa Margarida da Silva e Orta era amiga, teria como pano de fundo a vontade de chancelar $A s$

\footnotetext{
1 Ainda no ano de 1777, foi publicada outra edição das Aventuras de Diófanes. Nela, a autoria continua sendo atribuída ao pseudônimo Dorothea Engrássia Tavareda Dalmira, mas não existe menção a Fénelon.
} 
Aventuras de Diófanes sob a assinatura do influente secretário de D. João V. Tanto num caso quanto no outro, o nome desses homens cumpriria a função de "commodity", agregando capital (simbólico e/ou material) ao texto.

Se olharmos sob outra perspectiva, é possível ver nessas ações uma estratégia que visa, além da inserção, um modo de apresentação da obra no mundo das letras. Uma apresentação que se processa, por meio da nomeação da obra e da atribuição da autoria, com o objetivo de demarcar a existência nesse mundo. Como lembra Michel Foucault,

[...] um nome de um autor não é simplesmente um elemento em um discurso [...]; ele exerce um certo papel em relação ao discurso: assegura uma função classificatória. [...] o nome do autor funciona para caracterizar um certo modo de ser do discurso: para um discurso o fato de haver um autor [...] indica que esse discurso não é uma palavra cotidiana, indiferente, [...] mas que se trata de uma palavra que deve ser recebida de uma certa maneira e que deve, em uma dada cultura, receber um certo status. [...] A função autor é [...] característica do modo de existência, de circulação e de funcionamento de certos discursos no interior de uma sociedade (Foucault, 2009:274).

Alexandre de Gusmão e Fénelon surgem, segundo essa linha de raciocínio, com a função de filiar Aventuras de Diófanes a um determinado grupo discursivo, estabelecendo o modo de ser desse romance $e$ autenticando sua existência, consoante os paradigmas atrelados à escrita no século XVIII. Não obstante os benefícios que essa estratégia poderá ter trazido à obra naquele momento, ela se converte, em alguma medida, no apagamento de Teresa Margarida da Silva e Orta enquanto escritora. ${ }^{2}$

2 Essa mudança do nome da autoria fez com que Ernesto Ennes (1952), como também Teófilo Braga (1984) e Maria de Santa-Cruz (2002) conjecturassem que a obra seria de dupla autoria, ou até mesmo colocassem em causa a autoria plena de Teresa Margarida. Mas trata-se de uma interpretação errônea. Segundo Conceição Flores, "a postura dos dois estudiosos revela misoginia, pois ambos 
Para compreender tal operação, é preciso ter em mente dois aspectos que caracterizam o contexto cultural dessa época. Em primeiro lugar, assinar um livro é um gesto carregado de riscos, não significando apenas autenticar uma autoria, mas também se submeter às instâncias que regulam a produção/circulação dos escritos. Mais que meramente atribuir um dado texto a uma determinada pena, trata-se de uma exigência jurídica que individualiza uma obra e a torna responsabilidade de alguém. Em segundo lugar, a cultura escrita é, nesse momento, um espaço predominantemente associado ao gênero masculino. Em Portugal, a escrita de autoria feminina fica concentrada, conforme Isabel Sá (2011), ao espaço conventual, onde prevalecem obras poéticas ou, mais frequentemente, textos que narram experiências místicas, contam histórias de santos, conventos e ordens religiosas, na esteira de Santa Tereza d'Ávila (1515-1582). É somente nesses termos que a produção escrita de mulheres obtém reconhecimento, o que torna esses tipos de texto "importantes bens no mercado do prestígio religioso e social" (Sá, 2011:287). Em contrapartida, a prática feminina de outros gêneros literários, como o romance, não é facilmente chancelada, figurando muito habitualmente como exceção e/ou transgressão. $\mathrm{O}$ seu reconhecimento enquanto prática de escrita aceitável para mulheres enfrenta bastante resistência, o que o torna, não raro, alvo de alguma ação de apagamento.

Nesse cenário, a escrita de autoria feminina está, portanto, sob dupla interdição de gênero (identidade e forma literária), já que transitar pela escrita é, por si só, uma atividade associada com maior frequência ao universo masculino $e$ o manuseio do gênero romance não figura no rol das práticas de escrita outorgadas às mulheres, comumente aconselhadas a sequer ler romances. Assim, parece justificável que Teresa Margarida da Silva e Orta, na condição de escritora e romancista, tenha se apagado em relação

consideram a obra excelente, por isso não conseguem dissociá-la da autoria masculina de Alexandre Gusmão, figura de prestígio intelectual e político da corte de D. João V" (Flores, 2006:151). 
à autoria de seu texto, e tenha feito isso como resposta à dupla interdição que sua assinatura pudesse acarretar.

Todavia, cabe destacar que esse apagamento se desenrola de forma oblíqua, pois não se limita a encobrir, mas também faculta uma estratégia de afirmação, perfazendo um movimento ambíguo no qual ocultar e apresentar são as interfaces de uma mesma totalidade. É pouco provável que Teresa Margarida da Silva e Orta tenha se valido de Gusmão e Fenélon para singularizar sua escrita com a marca de sua ausência. Antes, o ato de se encobrir nessas personalidades camufla uma plataforma de apresentação de si mesma. Ainda que a ideia de emulação estivesse em voga nessa época, tendo inclusive sido invocada no título da edição de 1777 das Aventuras, apresentada como imitação do "sapientíssimo Fénelon", ${ }^{3}$ o processo de escrita desse romance já se situa num período em que "composições literárias não são mais pensadas como [...] histórias que foram reutilizadas, lugares-comuns que foram compartilhados [...]" (Chartier, 2014:129). Toda obra é, como defende Diderot em seu Mémoire sur le commerce de la librairie, propriedade legítima de seu autor, expressão irredutivelmente singular dos seus pensamentos $e$ sentimentos, o que reforça ainda mais a hipótese de que Gusmão e Fenélon cumprem a função de selo editorial e artifício para contornar prováveis interdições de gênero que viessem a incidir sobre Silva e Orta.

A operação de camuflagem que está na base da publicação das Aventuras de Diófanes e que, em última análise, se converte em princípio estruturante da obra, enseja analisá-la a partir da entrada no campo da condição feminina, evidenciando a reação ambígua da escritora/romancista a um contexto desfavorável, de maneira a demonstrar o movimento de ocultação e afirmação do

${ }^{3}$ Por emulação, entenda-se não apenas imitar, mas também uma tentativa de superar o que se imita. A utilização desse termo é bastante sintomática da ambiguidade envolvida na imitação que Teresa Margarida empreende em relação ao texto de Fénelon. Ela abre caminho para pensar esse ato enquanto reprodução de um modelo discursivo tipicamente masculino, na esteira de um autor reconhecido, mas também como superação desse modelo. 
feminino. Movimento esse que envolve disfarçar o romance como imitação de um autor consagrado, na impossibilidade de tomar a escrita de uma mulher como parâmetro de imitação, e o disfarce do feminino sob uma roupagem masculina.

Já no prólogo, surge uma voz que se dirige ao leitor pedindo desculpas pelos erros encontrados na obra, justificando que isso se deve ao fato de ser de uma mulher a mão que a escreve, deixando entrever que o gênero feminino é dotado de uma incapacidade inata, pois falta-lhe "os pincéis de Apeles e [...] a pena de Homero" (Orta, 1945:1), isto é, uma desenvoltura igual ou superior à masculina, o que fortalece a ideia de imitação como decorrência da inabilidade das mulheres. Nesse ponto, poderíamos pensar que Teresa Margarida cumpre aquilo que é quase referência em textos de mulheres dessa época: assumir a inferioridade feminina, tal como assim fizeram, a título de exemplificação, Bernarda Ferreira de Lacerda (1595-1644) e Soror Maria de Mesquita Pimentel (1581-1661), reforçando os estereótipos de gênero, os quais se baseiam na atribuição de papéis sociais a partir das crenças estruturadas sobre as atividades próprias que cabem ao homem e à mulher, a partir de traços de género e características psicológicas que se atribuem a cada sexo (Neto, 1999:9-11). Acima de tudo, a relação do estereótipo com o gênero atribui certos traços e papéis ao homem e à mulher, $e$ isso acontece, segundo Susana Costa e Susana Marta Santos (1997), porque utilizamos informações armazenadas na nossa memória para dar sentido aos estímulos que recebemos do mundo social no qual estamos inseridos.

Embora o pedido de desculpas de Tereza Margarida leve a pensar na aceitação da ideia de que a escrita é uma atividade mais adequada para o homem, ele também pode ser resultado da técnica retórica conhecida como captatio benevolentie, que visa angariar a benevolência do leitor para um texto buscando persuadi-lo a relevar as insuficiências do autor. Na verdade, o que se pretende não é pedir desculpas, mas valorizar o texto ao minimizar, em aparência, a importância do autor. Esse mecanismo é largamente utilizado desde a antiguidade, tanto por homens 
quanto por mulheres. Ao usá-lo no prólogo das Aventuras, Teresa Margarida parece explorar o estereótipo da desvantagem social da mulher, simulando validá-lo. No entanto, demostra estar mais interessada em atribuir valor ao seu texto e, em última instância, minar essa desvantagem. Como lembra Casares (2008), os estereótipos de gênero (atribuições sociais aos sexos) criam modelos vazios numa estrutura de contrastes e relações, na qual se incluem noções e valores que podem ser manipulados e utilizados para um devido fim. Tereza Margarida demostra ter consciência desses estereótipos e de como eles incidem sobre as práticas de escrita e recepção da obra literária, o que a leva aparentemente a reforçá-los, buscando manipulá-los com a finalidade de reverter a desvantagem imputada ao fato de ser mulher. Ao mesmo tempo, integra-se à imagem socialmente acordada que liga o gênero feminino a limitações face à escrita, e inverte a lógica de pensamento em que se ampara esse estereótipo, abrindo espaço para se reconhecer o peso e o valor que um texto escrito por uma mulher tem.

Avançando na direção do texto propriamente dito, é possível notar um enfoque especial em torno das personagens femininas. Embora o título do romance ressalte um conjunto de ações de um homem - Diófanes, o rei de Tebas -, o protagonismo está posto na figura da sua filha, Hemirena. Ora, essa operação é sintomática de um universo em que a mulher, mesmo que em posição de protagonista, se dispersa na sombra de um homem, carecendo do nome deste para atestar sua existência, assegurando assim a virilidade masculina como válida e reconhecida pelos romances tradicionais. Efetivamente, são as aventuras da filha que se destacam como eixo central do romance e não as de seu pai. Ao longo das seis partes que compõem o romance, também chamadas de livros, a ação principal se concentra no desterro vivido por Hemirena e no subsequente périplo que ela realiza na região do mar Egeu para regressar à terra natal.

Prometida ao príncipe Arnesto de Delos, Hemirena segue juntamente com a familia para celebrar seu casamento. No entanto, a esquadra que os levava passa por uma forte 
tempestade, arrastando-os até Argos, onde Hemirena e sua mãe, Climeneia, são escravizadas durante três anos, ao passo que o pai é vendido, também como cativo, para Corinto. Passado algum tempo, Hemirena é adquirida, em Atenas, pela princesa Bereniza, que, admirada com a nobreza de seu porte, resolve integrá-la às damas da corte, permitindo-lhe viver um período de sossego, que é interrompido quando o príncipe Ibério decide pedi-la em casamento, oferta prontamente recusada em nome do compromisso firmado com Arnesto.

Temendo não ter sua recusa levada em conta, Hemirena decide fugir em direção a Corinto, onde assume uma identidade masculina, passando a se chamar Belino. Durante a estada nessa cidade, vive em companhia de Antionor, um homem de aspecto envelhecido e asqueroso em cuja figura Diófanes se ocultara. Sem saber que estava ao lado do pai, ela teme que seu disfarce seja notado pelo suposto ancião, o que a leva a fugir novamente. Dessa vez, adota como destino uma aldeia de pastores em Argos, local em que vive por quatro anos com sua mãe, mas também sem saber, já que Climeneia também havia recorrido a um disfarce, assumindo o nome de Delmatra, uma austera e sábia senhora. $\mathrm{O}$ ambiente pastoril propicia outro período de tranquilidade a Hemirena, situação que muda quando a pastora Atilia busca se casar com ela, acreditando estar diante de um homem, obrigando-a a ir embora.

Em Esparta, para onde vai, a identidade masculina acaba por forçá-la a ingressar na carreira militar e participar de uma guerra, experiência que, mais adiante, se torna fundamental para que ela coloque em liberdade a sua mãe, então presa em Corinto, $e$ trace a viagem de volta para Tebas, em cujo trajeto reencontra o pai, ocasião em que se despe do disfarce que havia vestido. Por fim, eliminados todos os entraves, o príncipe Arnesto é reencontrado e ocorre a celebração do casamento, já que Hemirena triunfou sobre todas adversidades, mantendo-se em irrepreensível estado de virtude.

Ressalta dessa intriga um investimento mimético voltado à representação da condição feminina. Os acontecimentos-chave se 
associam intimamente ao como é e o que é ser mulher no universo setecentista. Inicialmente, essa problemática é evocada pelo casamento, instituição que direciona boa parte da vida da mulher em sociedade. É precisamente o casamento de Hemirena que motiva o desterro e o périplo vividos por ela, situação que é representativa da importância que esse evento tem. Isso aponta para uma pauta existencial orientada pela busca desse acontecimento e a solução dos nós que ele acarreta. Tanto é assim que, ao final, a recompensa que Hemirena recebe é, além de regressar à terra natal, poder se casar, evento indissociavelmente ligada à ideia de triunfo feminino.

Para a obtenção do prêmio, é indispensável que Hemirena prove ser capaz de seguir um padrão de comportamento $e$ educação reservado às mulheres, encaminhando-se incansavelmente pelos ditames da virtude. Já no começo da narrativa, o pai apresenta-lhe o norte feminino, isto é, o que é ser mulher. Colocando-se como porta-voz dos valores de gênero vigentes, ele a aconselha observar a educação que recebera, conservando-se no exercício da virtude, no amor ao decoro e desprezo pelo ócio. Esses valores também são referendados pela mãe, que adverte para as periculosidades das ações femininas quando não seguem os condicionantes de gênero: "A natureza dotou os homens de mais forças e as mulheres de mais subtilezas do espírito; e às que se servem dela entregues ao ócio, incita paixões ardentes que arruínam o entendimento" (Orta, 1945:68). Essas subtilezas de sentimentos aparentam ser uma alusão evidente à sentimentalidade como atributo feminino, que deve ser evitada como entrega, visto que, exacerbada, pode levar as mulheres a sucumbirem a um desejo ignóbil, ou seja, renegando assim os preceitos estabelecidos.

Apesar de validar esses estereótipos de gênero, Climeneia também os questiona. Ela refere que um dos perigos que levam as mulheres a se desvirtuarem é a ociosidade e a vaidade, em consonância com o pensamento hegemônico. No entanto, defende a instrução feminina, contrapondo-se a esse pensamento: "Nós não temos a profissão das ciências nem obrigação de sermos 
sábias, mas também não fizemos votos de sermos ignorantes" (Orta, 1945:66), quase que como uma resposta à associação de sabedoria e do letramento como obrigação e atributos próprios dos homens, reivindicando $\mathrm{o}$ direito às mulheres pelo conhecimento, sem distinção dos gêneros. Nessa mesma direção, ela se recusa a aceitar como traços inerentes às mulheres a ignorância, a maldade e a loucura, "qualidades com que os homens dizem mal [das mulheres]" (Orta, 1945:68). Além disso, Climeneia critica a relação matrimônio/patrimônio estabelecida pelos "pais, que cegos pela avareza, e encantados [por] seus interesses, casam as filhas [...] com maridos cheios de vícios $e$ achaques" (Orta, 1945:76); e coloca a responsabilidade do ambiente doméstico como algo que deve ser partilhado igualmente por homens e mulheres, posicionamentos que adquirem significado contestatório face a uma ordem que se baseia na estrita divisão de tarefas e espaços entre homem $e$ mulher, interditando o acesso desta última aos lugares públicos $e$ colocando o lar sob sua prerrogativa.

Aparentemente, estamos diante de uma contradição, já que Climeneia vocaliza dois pontos de vista opostos, validando a condição da mulher segundo os paradigmas socialmente aceitos e, ao mesmo tempo, colocando-os em causa. Contudo, parece se tratar de mais um momento em que o mecanismo da ambiguidade se faz presente na economia das Aventuras de Diófanes. Nessa direção, cabe destacar que o posicionamento ambíguo reside na fala de uma personagem feminina, ao passo que na de Diófanes ele não é perceptível, o que nos leva a pensar em mais uma vantagem social do gênero masculino: a liberdade para expor, sem maiores constrangimentos, as opiniões. Daí provavelmente a necessidade da voz feminina se valer do movimento dialético apresentar/ocultar, validar/questionar.

Esse movimento é sintomático do como é ser mulher. Ele está representado de forma mais evidente e aprofundada na trajetória de Hemirena. Isso se dá especificamente quando ela se veste de homem para escapar às pretensões do príncipe Ibério. Nesse momento, diz a voz que narra: "saiu com vestido de 
homem, disposta com aquele fingimento a vencer os maiores assaltos de sua cruel fortuna" (Orta, 1945:36). Separada do pai, impossibilitada de se casar e, agora, sem a proteção de Beraniza, ela se vê numa situação bastante delicada, pois precisa se conduzir exclusivamente por conta das suas condições pessoais. Assim, a única alternativa encontrada é assumir uma identidade masculina, o que lhe permite prescindir da proteção de um homem e se colocar sob sua própria tutela. É precisamente graças à camuflagem que ela consegue fazer frente às contrariedades que se apresentam e permanecer intacta até o final do périplo, credenciando-se a ao casamento com o príncipe Arnesto.

Em determinada altura, Hemirena chega a justificar essa estratégia como único meio de transitar por um mundo que, sob império dos homens, priva as mulheres da liberdade de escolher:

Não me culpeis o haver usado da dissimulação de tais vestidos; porque como os maiores trabalhos, e desgraças, que acontecem às mulheres, são originadas pelos enganos dos homens, que ou cegos de amor, ou de seus desordenados costumes, lhes prendem a liberdade, $e$ as encaminham aos precipícios, pareceu-me que só escondendo-me assim aos seus olhos, caminharia com menos risco (Orta, 1945:171-172).

Assumir uma identidade masculina é uma operação que impõe custos a Hemirena, pois "os fingimentos ainda quando necessários, não deixam de dar trabalho" (Orta, 1945:207). O principal deles é desativar o aspecto plástico do corpo feminino, sobretudo na dimensão físico-sexual, o que não deixa de acarretar problemas, tais como despertar a paixão de outras mulheres, como ocorre no episódio da pastora Atília, e a necessidade de guerrear em Esparta. Por outro lado, essa androginia é, talvez, necessária para demonstrar que, através de uma figura masculina, a personagem delicada $e$ inocente (provida de forte sentimentalidade) poderia tornar-se corajosa e destemida diante de uma vida de amarguras e fugas, demonstrando níveis variáveis de sentimentos e de comportamentos. 
Aliás, Sofia de Melo Araújo acredita que as aventuras de Hemirena ilustram, em vários sentidos históricos do texto, a seguinte dinâmica intencional de Teresa Margarida:
a forma como a mulher ideal conjuga as qualidades ditas femininas da formosura (beleza, graça, pureza, decoro, dedicação, lealdade, carinho) $e$ as qualidades ditas masculinas da virtude (força, valentia, heroísmo, persistência, equilíbrio) (Araújo, 2008:110),

o que acaba por colidir com a lógica social vigente, assentada, como se sabe, na separação dos sexos e na rígida divisão de atribuições que recai sobre cada um. Por seu turno, Maria de Santa-Cruz tem uma outra interpretação dessa dinâmica:

Tradicionalmente, a mulher vestida de homem identifica-se a esse compromisso entre Deus e o Diabo, em que, evidentemente, o diabólico representa a parte feminina e o brilhante a manifestação do masculino, embora sejam ambos de proveniência dúbia no que respeita a sexo ou género (Santa-Cruz, 1990:34).

De qualquer forma, estamos face a uma narrativa perpassada por ambiguidades e cheia de máscaras, na qual as personagens, mesmo de cunho tão íntimo, como pai, mãe e filha, se camuflam ao longo de quase toda a trama. Uma narrativa, por essa razão, representativa de um mundo em que, para conviver com situações estranhas à ordem estabelecida, a mulher precisa recorrer a uma afirmação de si mesma que se processa contiguamente a um estratagema de ocultação. Por isso, a necessidade de masculinização de Hemirena.

Apresentadas algumas estratégias do disfarce do feminino sob uma roupagem masculina em Aventuras de Diófanes, cabe agora demostrar como essa obra se camufla sob a pecha de imitação das Aventuras de Telêmaco. Sobre esse aspecto, é interessante observar que é apenas a partir da segunda edição que Fénelon é indicado como modelo desse romance. Possivelmente, 
terá contribuído para isso o fato da recepção à primeira edição das Aventuras de Diófanes tê-la vinculado, positivamente, às Aventuras de Telêmaco. Em 1752, quando foi publicado pela primeira vez, a Gazeta de Lisboa escreve uma nota que o descreve como uma obra que "imita ou excede ao Sapientíssimo Fénelon na sua viagem de Telêmaco fazendo-se digna das mais atenciosas venerações". Poderá ter sido esse o ponto de partida para a presença de Telêmaco nas duas edições seguintes, levando-se em conta a relevância do autor francês e os dividendos que sua imagem poderiam acrescentar às Aventuras de Diófanes.

Cabe lembrar que, entre a primeira e a segunda edição, Teresa Margarida passou por uma série de turbulências em sua vida pessoal. Em 1753, o seu marido morre, deixando-a numa situação financeira bastante complicada e com a incumbência de criar 12 filhos. Anos mais tarde, em 1770, ela foi presa no convento da Ferreira (Lisboa), onde ficou até 1777, por ordem do marquês de Pombal e sob a alegação de ter mentido ao rei $\mathrm{D}$. José I. Nesse quadro, encontrando-se privada de sua liberdade e desprovida da tutela do marido, ela certamente deve ter tentado se resguardar de problemas jurídicos e procurado criar condições para a boa aceitação do seu romance. Nesse sentido, o nome de Fénelon - um homem - se torna providencial, pois estabelece um pacto estratégico que põe à obra em liberdade e sob a tutela de uma pessoa juridicamente autorizada.

Dito isso, vejamos o sentido que a imitação adquire nas Aventuras de Diófanes em relação às de Telêmaco. Não obstante a incidência de elementos comuns a esses dois romances, como a construção de uma fabulação que tem por base um périplo ambientado no mundo grego, a heroicidade excepcional e o cariz didático, a presença de Fénelon é incorporada como artifício e não como substrato na obra de Teresa Margarida. Trata-se, acima de tudo, de uma vinculação fetichista, resultante de um movimento teatral que procura inscrever as Aventuras de Diófanes, ou melhor, o seu processo de escrita e a sua circulação num espetáculo midiático-ficcional. Enformada em Fénelon, um autor consagrado, essa obra o deforma, o decompõe internamente 
e se distancia dele, operação que lhe garante a constituição de uma forma particular.

Cada romance segue uma linha bastante diferente. Aventuras de Diófanes é um romance de provação, já Aventuras de Telêmaco é um romance de formação. O primeiro tipo, conforme define Bakhtin (2003), se constitui como uma série de provações que colocam à prova fidelidade, bravura, coragem, virtude, nobreza e santidade das personagens centrais, sempre apresentadas como inalteráveis. $\mathrm{O}$ mundo, nesse caso, se converte numa arena de provação que serve para atestar as qualidades dos personagens, que, dadas desde o início, são apenas verificadas $e$ experimentadas ao longo do romance. Partido de um ideal previamente estabelecido, essa natureza estática impede os personagens de vivenciarem qualquer processo de formação ou desenvolvimento, tornando-os uma grandeza constante. No segundo tipo, ocorre exatamente o inverso. Os heróis e heroínas são submetidos a experiências formadoras. "Todo o movimento do romance, todos os acontecimentos $e$ aventuras nele representados deslocam o herói no espaço, deslocam-no pelos degraus [...] da hierarquia social" (Bakhtin, 2003:218), convertendo-o em grandeza variável. O mundo aqui "não é apenas uma pedra de toque, mas também uma escola" (Bakhtin, 2010:186).

Em relação aos romances analisados, essas diferenças não se limitam a características meramente estéticos-formais. Sob o ângulo do gênero, elas são fundamentais para colocar em cena os sentidos que cada um atribui às noções de masculino $e$ feminino. $\mathrm{O}$ périplo de Hemirena, nesse sentido, se conforma enquanto um percurso destinado a certificar que ela corresponde a um modelo de feminilidade. Telêmaco, em contrapartida, segue uma trajetória voltada à aprendizagem e à incorporação de um sentido de masculinidade.

Os acontecimentos pelos quais a protagonista das Aventuras de Diófanes passa não são apenas entraves para se retornar a Tebas. Eles se revelam, em última instância, como empecilhos que ela precisa enfrentar para se manter intacta, provando que é uma 
mulher comprometida com o papel que lhe fora destinado, sendo capaz de se conservar em estado irretocável, conforme a admoesta o pai: "conserva sem desmaios as sólidas doutrinas da tua educação, o exercício das virtudes, [...] teme os Deuses, ama constantemente o decoro, despreza o ócio, e serve o teu destino" (Orta, 1945:10-11). E como é de extração nobre, ainda tem por obrigação reter "a lembrança da distinção, com que nasceste, para sempre serem nobre as tuas ações" (Orta, 1945:10-11), agindo segundo o padrão de comportamento ditado à mulher aristocrata. Como adiantado acima, Hemirena obtém êxito em sua empreitada, mantendo-se fiel aos princípios e inalterada em seus valores, o que nos leva a pensar que sua luta, acima de tudo, consiste em manter sua interioridade estática, vendando-se às mudanças, sempre identificadas como um atentado à sua integridade. Por agir assim, Hemirena acessa a condição que lhe está reservada - o papel de esposa -, evidenciando um dos sentidos possíveis para aquilo identificado com "o ser mulher".

Nas Aventuras de Telêmaco, a busca do protagonista pelo pai (Ulisses), que seria o argumento central do romance, pretexta, na verdade, aquilo que se coloca como fim último do seu périplo: a missão de se transformar, mais especificamente se tornar um homem. Nessa passagem, está implicada a necessidade de deixar algo para trás - a condição de jovem inexperiente $-e$ atingir outro patamar, o de um guerreiro apto a governar Ítaca. $\mathrm{O}$ sentido que a masculinidade adquire aqui está diretamente ligado a dois papeis atribuídos aos homens no contexto europeu do Antigo Regime: o guerreiro (soldado), detentor da virilidade, e o governante, detentor do poder.

É interessante notar que a aquisição da masculinidade é sempre rondada pelo perigo da feminilidade. Por diversas vezes, os oponentes de Telêmaco colocam em causa a sua virilidade, desqualificando-o como efeminado:

Falanto, a todo o momento, procurava contrapor-se a Telêmaco: nas reuniões da tropa, amiúde ele interrompia o que Telêmaco estava dizendo e fazia pouco dos seus 
conselhos, que apresentava como opiniões de um jovem sem experiência. Troçava de Telêmaco, tratava-o como se fosse um frouxo e afeminado (Fénelon, 2006:191).

Em outras ocasiões, quando Telêmaco é instruído sobre o comportamento que se espera de um homem, é confrontado com exemplos de guerreiros que sucumbiram por causa de atitudes efeminadas. Filoctetes lembra-lhe que Hércules, "que havia vencido tantos monstros, [...] [fora] dominado por um amor cego, [...] como se fosse o mais covarde e o mais efeminado de todos os homens" (Fénelon, 2006:178). Essa desvalorização do feminino ganha ainda mais corpo com a imagem negativa que se constrói da mulher, majoritariamente associada a algum tipo de dificuldade colocada entre Telêmaco e seus objetivos. É assim com a deusa Calypso, que procurar retê-lo em sua ilha; com a ninfa Eucharis, por quem ele se apaixona cegamente, conforme o narrador, a ponto de pensar em desistir do seu périplo; com Vênus, que mobiliza Netuno para causar tormenta no mar e o impedir de chegar até Ítaca; e com Astarbé, mulher de Pigmalião, que é retratada como um monstro. Nesse sentido, a afirmação da masculinidade para Telêmaco significa, dentre outras medidas, negar, controlar e/ou se proteger da feminilidade e dos males que são atrelados a ela. Desse modo, é possível encontrar nas Aventuras de Telêmaco, assim como nas Aventuras de Diófanes, um conjunto de valores associado à ideia de feminino, todavia com enfoque diferente, já que aqui o masculino se define por contraste ao que se concebe por feminino.

O processo de aprendizagem de Telêmaco é conduzido por Mentor, personagem que incorpora a deusa Minerva, umas das poucas figuras femininas que são pintadas positivamente. Ainda assim, o feminino é encoberto pela imagem de um homem. Essa relação perfaz uma interação pedagógica, posicionando Telêmaco na condição de aluno e Mentor na posição de preceptor. Isso é extremamente importante porque revela a masculinidade como construção didática, algo passível de ser ensinado e aprendido. Enquanto deus atuante, ou melhor, deusa, Mentor imprime a essa 
relação a particularidade de ser fruto da parceria que se estabelece entre o humano e o divino, ao contrário do que ocorre com Hemirena, em cujo percurso a presença dos deuses é meramente protocolar. Um protocolo pelo qual Teresa Margarida se desculpa no final do romance, quando escreve uma advertência em que esclarece que o "uso das palavras Deuses [...] [se dá] no sentido em que as têm usado muitos Católicos, somente para imitar, e fingir as fábulas, e termos dos antigos Gentios, que não chegaram a conhecer o verdadeiro Deus Trino" (Orta, 1945:267). Nesse sentido, os fios da vida de Hemirena são tecidos por ela mesma, ou melhor, ela tece solitariamente, como prova de sua energia interna e boa disposição para com os preceitos que recebera, os fios que deixam à sua disposição. O seu tutor é, na verdade, um conjunto de ensinamentos internalizados aos quais ela deve corresponder. Está-se, como adverte Diófanes, no domínio dos laços que são desatados pela mão do homem e não mais pelas de Atropos, divindade que, na mitologia grega, rege os destinos. Quando é auxiliada, o que é muito raro ocorrer, Hemirena conta com o apoio de humanos. De modo geral, as outras personagens a acompanham como espectadoras. Espectadoras interessadas em acompanhar seu desempenho ao longo da sucessão de provas a que é submetida.

A Hemirena, é vedado o erro. Qualquer desvio seria fatal. Tanto é assim que sua mãe, ao vislumbrar a hipótese de ela não se manter na rota da virtude, recomenda uma saída extremada: o suicídio. A admissão do erro representaria a alteração da sua constituição e a impediria de ser certificada como mulher, isto é, como alguém virtuosa e imune ao pecado. Com Telêmaco, esse quadro é totalmente diverso. O erro é admissível em seu percurso, já que está inserido num contexto pedagógico, sendo possível, até mesmo, tirar proveito dele. Ao final, Mentor parabeniza Telêmaco e justifica que os grandes erros cometidos serviram para aprender e obter conhecimento:

Filho de Ulisses [...] eu o guiei em naufrágios, em terras desconhecidas, em guerras sangrentas [...]. Eu lhe mostrei, 
com exemplos palpáveis, os verdadeiros e os falsos preceitos com que se pode reinar. Seus erros e seus sofrimentos foram úteis porque nenhum homem pode governar sabiamente se jamais sofreu e se não aprendeu com os padecimentos em que seus erros o precipitaram. (Fénelon, 2006:287)

O erro é o que permite alterar um estado de coisas, impelindo o aprendiz a mudar atitudes e a se refazer, o que, no caso de Telêmaco, significa se tornar homem e rei. Ser homem, nesse sentido, está ligado a se alterar. Ser mulher, em contrapartida, exige se manter, tal como se dá com Hemirena. Como lembram Ana Gabriela de Macedo e Ana Luísa Amaral, organizadoras do Dicionário da Crítica Feminista (2005), o feminino, ou o entendimento da feminilidade, englobaria um sentido relativo à imitação e à conformidade com os padrões sociais e sexuais tradicionalmente identificados como pertencentes às mulheres, ou seja, que lhes foram impostos historicamente

Vistos sob essa perspectiva, é possível concluir que as Aventuras de Diófanes e Telêmaco se situam em direções diversas, sobretudo no que se refere às concepções de gênero (masculino $e$ feminino) e de forma literária (romance). Aventuras de Diófanes se vale de uma estrutura romanesca que tem por base a história de uma protagonista feminina que busca se manter dentro de um modelo de feminilidade, bem como as contradições advindas dessa busca, expressas ainda que de modo ambíguo. Aventuras de Telêmaco, em contrapartida, tem por base a tentativa de um protagonista masculino de se transformar e alcançar um modelo de masculinidade, seguindo uma diretriz didática, em que não cabe apontar as contradições subjacentes a esse modelo. Por essa razão, a alegação de que o romance português foi realizado a partir da imitação do texto de Fénelon se sustenta com mais propriedade no âmbito de uma operação midiática, decorrente de uma estratégia de camuflagem de que Teresa Margarida da Silva e Orta se vale para organizar sua obra e expô-la. Cabe ressaltar que é possivel encontrar, tanto em Fénelon quanto em Teresa Margarida, visões estereotipadas sobre o que é ser masculino e o 
que é ser feminino, o que os aproximaria. Todavia essas visões são incorporadas de modos diversos. No caso do romancista francês, há a validação do que se entende por masculino e, por contraste, a ideia de feminilidade, sem que essas ideias sejam alvo de questionamento. Em relação à escritora portuguesa, existe um diálogo crítico, nos limites de uma estratégia de camuflagem, com os padrões de gênero, numa alternância entre fazer concessão a esses padrões e refutá-los.

\section{Referências bibliográficas}

Amaral, Ana Luísa; MACEdo, Ana Grabriela (orgs.). Dicionário da Crítica Feminista. Porto: Afrontamento, 2005.

ARAÚJo, Sofia de Melo. Aventuras de Diófanes, de Teresa Maragarida Orta e Silva - os ideais de Climinéia e Diófanes à luz dos tempos. Revista da Faculdade de Letras - Línguas e Literaturas (23), Porto, Universidade do Porto, 2006 [2008], pp.103-126.BAKHTIN, Michail. Estética da criação verbal. São Paulo, Martins Fontes, 2003. Tradução de Paulo Bezerra.

Braga, Teófilo. História da Literatura Portuguesa. Os seiscentistas. Lisboa, Imprensa Nacional - Casa da Moeda, 1984, vol. 3.

CASARES, Aurelia Martín. Antropologia del género: culturas, mitos y estereótipos sexuales. Madri, Ediciones Cátedra - Universidad de Valência, 2008.

Chartier, Roger. A mão do autor e a mente do editor. São Paulo, Editora Unesp, 2014.

COSTA, Susana; SANTOS, Susana Marta dos. Estereótipo da mulher em Portugal e sua relação com a discriminação sexual no trabalho. Lisboa, CITE, 1997.

ENNES, Ernesto. Dois paulistas insignes. Teresa Margarida da Orta e Silva e o primeiro romance brasileiro. São Paulo, Companhia Editora Nacional, 1952.

FÉNELON, François de Salignac de La Mothe. As aventuras de Telêmaco: filho de Ulissses. São Paulo, Madras, 2006. Tradução de Maria Helena Trylinski. 
Flores, Conceição. As Aventuras de Teresa Margarida da Silva e Orta em terras de Brasil e Portugal. Natal, Opção Gráfica, 2006.

FOUCAULT, Michel. Estética: literatura e pintura, música e cinema. Rio de Janeiro, Forense Universitária, 2009. Tradução de Inês Autran Dourado.

Neto, António et alii. Estereótipos de género. Prefácio de Constança Gomes Machado. Lisboa, Comissão para Igualdade e para os Direitos das Mulheres, 1999.

ORTA, Tereza Margarida da Silva e. Aventuras de Diófanes. Rio de Janeiro, Imprensa Nacional, 1945.

SÁ, Isabel dos Guimarães. Os espaços de reclusão e a vida nas margens. In: Mattoso, José (org.). História da Vida Privada em Portugal: A Idade Moderna. Lisboa, Círculo de Leitores, 2011, pp.276-299.

SANTA-CruZ, Maria. Crítica e confluência em Aventuras de Diófanes (1752). Tese (Doutorado em Literatura Brasileira), Universidade de Lisboa, 1990.

SANTA-CRUZ, Maria. Introdução. In: ORTA, Teresa Margarida da Silva e. Aventuras de Diófanes. Lisboa, Caminho, 2002, pp.15-76. 